\title{
REFUNDAR O ENSINO MÉDIO? ALGUNS ANTECEDENTES E ATUAIS DESDOBRAMENTOS DAS POLÍTICAS DOS ANOS DE 1990
}

\author{
Dagmar M. L. Zibas
}

\begin{abstract}
RESUMO: Partindo da premissa de que a escola média é um campo estratégico de luta onde as camadas populares têm construído seu direito à educação, o texto revisita a história dessa etapa de ensino e discute como foi tecida sua trajetória de avanços e recuos. $\mathrm{O}$ artigo detém-se nas políticas dos anos de 1990 e analisa algumas de suas diversas faces, trazendo, ainda, dados de três pesquisas que focalizaram a implementação da reforma. Com respeito à atuação do Governo Lula na área, o texto focaliza as principais inovaçōes introduzidas e aponta algumas das contradições do processo, inclusive aquelas que agora tornam mais nítida a distância entre os diferentes grupos que se opuseram às políticas do governo anterior.
\end{abstract}

Palavras-chave: Ensino médio. Reforma do ensino médio. Políticas para o ensino médio.

New foundations For High SCHOOL? A FeW past eXamples AND CURRENT DEVELOPMENTS OF THE POLICIES OF THE 1990s

ABSTRACT: Assuming that high school is the strategic field on which the working classes have fought to build their right to education, this paper reviews the history of this phase and discusses the steps forward and backward that shaped this trajectory. It focuses on the policies of the 1990s and analyzes some their various aspects. It also brings forth data from three researches that explored the implementation of the reform. As for the action of the Lula's administration in this area, it highlights the main innovations introduced and points out some contradictions in this process, specially those that clearly reveal the gaps between the different groups opposed to the previous government's policies.

Key words: High school. High school reform. High school policies.

* Pesquisadora da Fundação Carlos Chagas (FCC). E-mail: dzibas@fcc.org.br

Educ. Soc., Campinas, vol. 26, n. 92, p. 1067-1086, Especial - Out. 2005

Disponível em <http://www.cedes.unicamp.br> 
Refundar o ensino médio? Alguns antecedentes e atuais desdobramentos das...

$\mathscr{P}$

ara a análise dos problemas que, historicamente, afetam a ampliação e a qualidade da escola média brasileira, torna-se necessária talvez mais do que para o estudo de outras etapas do sistema de ensino - a referência ao clássico conceito de educação como um campo de luta cujas contradições podem tanto reforçar a estratificação social quanto contribuir para a democratização.

De fato, se o nosso sistema de ensino primário, tendo como ideal a escola republicana francesa do final do século XIX, conseguiu, ao longo de sua história, algum consenso quanto às suas finalidades e conteúdos, objetivando instituir uma racionalidade moderna e um sentimento de unidade nacional, foi a ampliação do acesso ao ensino secundário que concentrou a resistência dos setores conservadores, colocando a nu uma área de profundos conflitos, cujos desdobramentos ficam evidentes ao longo da história do ensino médio, estando hoje muito presentes na crueza do embate político-ideológico que permeia a recente reforma.

$\mathrm{Na}$ década de 1930, quando, apoiada por amplos setores sociais, uma incipiente estrutura de ensino primário público começou a se delinear em grande parte do território nacional, muitos expoentes da sociedade, da burocracia estatal e da cultura não se pejavam em defender a necessidade da preservação da característica elitista do ensino secundário. Segundo Almeida Jr. (apud Sposito, 1984, p. 43), "dominou, na administração escolar e nos meios pedagógicos primários, o princípio segundo o qual a educação secundária, que é um luxo aristocrático, deve ser abandonada pelo Estado à iniciativa particular”. A desenvoltura de posicionamentos desse tipo tinha, sem dúvida, como substrato cultural, o modelo do "liceu" francês, destinado às elites condutoras, e centrado nas humanidades e na transmissão da cultura greco-romana.

A luta popular, que nos meados do século XX, em São Paulo, visou à ampliação dos dois ciclos do então chamado ensino secundário, foi analisada de forma muito bem fundamentada no conhecido trabalho de Sposito (1984). Aqui basta lembrar que, na época, as pressões populares, às vezes estrategicamente aliadas a políticos populistas, foram aos poucos reduzindo as ações das elites que, abertamente, buscavam razões para impedir que a maioria da população avançasse em sua escolarização para além das quatro séries do ensino primário.

Em contrapartida, a desvalorização do ensino técnico-profissional tem raízes histórico-sociais bastante conhecidas. Um dos veios de tal herança está na nossa adesão, anteriormente já mencionada, ao modelo edu- 
cacional francês, cuja história é marcada por uma "longa resistência ao ensino técnico e profissional e de um relegar esse ensino para as carreiras desvalorizadas; um confinamento simbólico (...)" (Dubet, 2003 p. 32). Nesse contexto, é bastante reveladora a legislação brasileira que, até a década de 1960, vedava - para os concluintes dos cursos técnico-agrícolas e comerciais - e limitava - para os diplomados nos cursos técnico-industriais - a continuação de estudos em nível universitário.

Nos fins dos anos de 1960 e início dos de 1970, o embate político-ideológico que constrói a história do ensino médio sofreu uma reviravolta. A matriz de tal guinada estava, entre outros aspectos, no crescente desprestígio do "modelo francês" entre nós - principalmente em vista da chegada de novos contingentes populacionais ao ensino secundário -, bem como na influência de conselheiros de agências internacionais. Moura e Castro (2005, p. 154) assim se refere à participação do Banco Mundial na elaboração das políticas na década de 1970: "Em torno de 1971, estava em meu escritório do IPEA quando chegou uma visita do Banco Mundial. O homem estava muito orgulhoso das novas políticas que o banco traçara para investir num ensino técnico e abrangente (nos moldes da comprehensive school americana) no Brasil (...)".

Em consonância com o padrão preconizado pelos assessores estrangeiros, Roberto Campos, ministro do governo militar, já defendia, em 1968, que o ensino secundário deveria perder suas características de educação humanística e ganhar conteúdos utilitários e práticos, atendendo ao povo (e, evidentemente, às necessidades da produção), ao passo que o ensino superior se destinaria, inevitavelmente, às elites (Ghiraldelli Jr., 1994). Essa focalização no mercado parecia "cair como uma luva” para a solução do problema criado pela crescente pressão à expansão de vagas nas universidades públicas, pressão exercida, na época, por setores médios até então alijados do ensino superior.

Com essa orientação, a Lei n. 5.692/71, que instituiu a profissionalização compulsória no ensino de $2^{\circ}$ grau, abriu duas frentes inusitadas e contraditórias de enfrentamento político-ideológico. De um lado, as camadas médias resistiam profissionalizar seus filhos já na escola secundária, insistindo na manutenção da função especificamente propedêutica dessa etapa. Por outro lado, os setores populares ressentiam-se tanto da falta de condições materiais e técnicas básicas para a profissionalização universal pretendida quanto do enfraquecimento da capacidade propedêutica do ensino médio. 
Refundar o ensino médio? Alguns antecedentes e atuais desdobramentos das...

A “cassação branca" - por meio da Lei n. 7.044, de 1982 - daqueles artigos da legislação de 1971 que instituíram a profissionalização obrigatória no ensino de $2^{\circ}$ grau significou, principalmente, a esperada vitória dos segmentos médios em favor de seu objetivo de garantir um percurso escolar mais longo para seus filhos.

Nos anos de 1990, a luta em torno do significado do ensino médio ganhou nova intensidade. $\mathrm{O}$ embate principal, como se sabe, deu-se no processo de elaboração da nova Lei de Diretrizes e Bases da Educação Nacional (LDB), que, fundamentada na Constituição de 1988, deveria substituir a LDB de 1961. A mobilização para uma nova LDB acontecia concomitantemente a grandes mudanças nas relações de força no âmbito internacional. A débâcle do socialismo real e o conseqüente fortalecimento da hegemonia norte-americana trouxeram a consolidação da influência de organismos internacionais na construção das políticas nas mais diversas regióes do mundo. Com respeito à América Latina, multiplicaram-se os documentos das agências multilaterais, principalmente aqueles elaborados pela CEPAL e pelo Banco Mundial, os quais, com algumas diferenças de abordagem ou de ênfase, com análises mais focais ou mais amplas, faziam críticas contundentes ao papel tradicional do Estado na educação latino-americana e propunham mudanças importantes nessa área. O suposto sucesso do modelo chileno de financiamento público de escolas privadas tornou-se, nos meados da década de 1990, o leitmotiv dos defensores da reforma.

Os discursos internacionais repetiam incansavelmente dois bordões: a) a importância da educação básica (no Brasil, reduzida à escola fundamental) para o novo padrão de desenvolvimento dos países periféricos e b) a necessidade de o Estado tornar-se menos provedor de financiamento e mais indutor de qualidade, por meio de diversos mecanismos de controle, tais como avaliações externas do sistema e a convocação dos pais e da sociedade para participação tanto do financiamento quanto da gestão escolar. Nesse cenário, não se previa que a aproximação entre a instituição escolar e as famílias contribuísse para construção da cidadania ou de um espaço público democrático. $\mathrm{Na}$ verdade, o projeto visava a transformar as relaçóes entre os sujeitos da cena escolar de forma que os pais e alunos se tornassem clientes e os professores e gestores assumissem o papel de prestadores de serviços, inserindo, assim, na escola a lógica do mercado. O apelo à cidadania, entretanto, não desaparecia, mas era distorcido, por meio da intensiva convocação ao trabalho voluntário dos 
pais e de outros membros do entorno social, chamados a substituir a ação do Estado como "amigos da escola".

Entre nós, houve um movimento de adesão de importantes intelectuais, até então considerados de esquerda, à tese da mudança do papel do Estado na educação, privilegiando a iniciativa privada. Uma destacada voz nessa pioneira "mutação" político-ideológica foi a de Guiomar Namo de Mello. Já em 1990, uma pequena coletânea (Mello, 1990) marca a reviravolta, apontando a transição de uma história pessoal de defesa da exclusividade das escolas públicas no recebimento de recursos estatais para uma argumentação favorável ao financiamento público de escolas privadas de ensino médio. Um dos artigos desse mesmo livro, intitulado "A nova LDB, necessária, mas não às pressas", também já indica a resistência que estava se formando contra a gestação do projeto da nova Lei de Diretrizes e Bases da Educação Nacional, gestação que mobilizava profissionais e setores progressistas da sociedade. Ou seja, também com relação à nova LDB, o livro de Mello (1990) foi arauto da nova correlação de forças que se formava. Como conseqüência, o primeiro projeto da LDB, inspirado na Constituição de 1988 e construído de forma muito democrática, acabou sendo atropelado por uma outra formulação, elaborada nas esferas oficiais e oficiosas, e que se aproximava das recomendaçōes das agências internacionais. Castro ${ }^{1} \&$ Tiezzi $(2005$, p. 126) reconhecem que "a matriz de inspiração da reforma brasileira, concretizada por meio da nova LDB, sancionada em 20 de dezembro de 1996, e nos decretos posteriores, foi o novo paradigma educacional que passou a orientar a maioria das reformas educativas de ensino médio e profissional no mundo durante os anos de 1990".

A lei aprovada abandonou a principal característica do primeiro projeto no que dizia respeito ao ensino médio, pois não enfatizou a instituição do trabalho como princípio educativo e orientador de todo o currículo. A nova $\mathrm{LDB}$, embora indique que a formação profissional de qualidade só se faz mediante uma sólida educação geral, contém suficientes ambigüidades para permitir que legislação complementar instituísse novamente estruturas paralelas de ensino. Ou seja, deixou espaço para que o decreto do governo federal n. 2.208, de 1997, determinasse que a formação técnica, organizada em módulos, fosse oferecida separadamente do ensino médio regular.

A dualidade estrutural restabelecida foi justificada de diversas formas pelos especialistas ligados ao MEC e às agências multilaterais. Cláu- 
Refundar o ensino médio? Alguns antecedentes e atuais desdobramentos das...

dio de Moura e Castro, por exemplo, em um texto provocativo, parece escancarar a vertente ideológica das políticas dos anos de 1990 para o ensino médio e técnico quando afirma o seguinte:

(...) escolas industriais requerem ambientes distintos daqueles onde prospera o estudo das declinaçôes, da ortografia e dos verbos irregulares (...). O segundo grau recebe alunos com níveis de aptidão muito diferentes e tem de oferecer a eles as opçôes de ir trabalhar ou de entrar no ensino superior. Se os alunos têm aptidōes diferenciadas, colocá-los todos juntos não pode dar certo. Assim, é necessário acomodá-los em lugares diferentes e em programas diferentes. (Moura e Castro, 1995, p. 133 e 135. Grifos meus)

A extemporânea referência ao "estudo das declinações" sugere um "ato falho" nostálgico quanto ao modelo francês, elitista, de liceu. A afirmação de que a separação entre os alunos que seguem estudos universitários e aqueles que devem ingressar precocemente no mercado de trabalho se deve apenas a uma questão de "aptidões diferenciadas", nada tendo a ver com a origem de classe dos jovens, é uma miopia ideológica tão marcante que dispensa outros comentários.

A dupla função de Moura e Castro, como funcionário do BID e assessor do MEC, foi decisiva para a implementação da política que promoveu a desarticulação entre o ensino médio e o técnico. Nas palavras daquele economista:

Nessa época [meados de 1990], eu era funcionário do BID e também assessorava o ministro em questôes de políticas educacionais (...). O fator decisivo para fazer eclodir a mudança foi a possibilidade de um empréstimo de 250 milhões de dólares do BID. Um empréstimo pode ser uma arma poderosíssima para superar um impasse político. (Moura e Castro, 2005, p. $160,161,162)$

O elo personalizado entre o BID e o MEC dá razão a Cunha (2002) quando argumenta sobre a necessidade de não se "demonizar" as agências multilaterais, sendo imprescindível sempre levar em consideração a trama - muitas vezes inextrincável - de interesses locais e internacionais que tecem nossas políticas. Corrobora, também, a afirmação de Frigotto \& Ciavatta (2004a) quanto à continuidade da intervenção externa “(...) não direta e brutal, como no tempo da Colônia, mas consentida e associada (...) por meio de recursos e de ideologias (...)" (p. 14). Moura e Castro (2005), mais uma vez, é explícito sobre o tema: 
(...) os bancos têm o direito de não oferecer um empréstimo, a menos que o país esteja disposto a aceitar certas condiçōes (...). [As condicionalidades] podem até ser uma bênção para um ministro que tenha de lidar com recalcitrantes e não consiga pagar o preço político de um confronto direto. Uma condicionalidade positiva reflete os desejos do ministro - e, quem sabe, as necessidades do país -, mas permite que a "culpa" recaia sobre os bancos. (p. 162)

Adicionalmente, é necessário ainda destacar a importância do trabalho de Guiomar Namo de Mello no Conselho Nacional de Educação. Encarregada de relatar o Parecer do Conselho que explicitaria as novas Diretrizes Curriculares Nacionais para o Ensino Médio (DCNEM), essa especialista elaborou um documento muito bem articulado (Parecer n. 15/ 98), o qual, como se sabe, passou praticamente incólume por diversos fóruns de discussão, não incorporando qualquer crítica e sendo transformado, quase sem modificações, na Resolução n. 3/98 do Conselho.

A relevância desse documento não pode ser minimizada e seu objetivo muito nítido de "refundar" o ensino médio já foi analisado detidamente por inúmeros pesquisadores ${ }^{2}$, o que torna dispensável, aqui, uma abordagem mais detalhada. $\mathrm{O}$ que vale enfatizar é que a característica mais importante da Resolução n. 3/98 do CNE diz respeito à sua complexa estrutura híbrida, que, aderindo incondicionalmente ao discurso internacional dominante, foi capaz de acenar para alguns princípios caros aos educadores progressistas, tais como: a necessidade de contextualização e de menor fragmentação dos conteúdos, algum grau de autonomia da escola para definição do currículo, a importância pedagógica, política e social do protagonismo juvenil, a centralidade da preparação ampla para o trabalho e para a cidadania. No entanto, tais princípios vêm articulados aos objetivos da pedagogia das competências, a qual, como se sabe, prioriza a construção de um novo profissionalismo (Ramos, s/d.) e de novas subjetividades, centrando-se em esquemas cognitivos e socioafetivos que promovam a constante adaptação e readaptação dos jovens tanto às mutantes necessidades de produção quanto à redução, dita inexorável, do emprego formal. Nessa abordagem, a responsabilidade pela superação do desemprego e de outras desigualdades sociais fica a cargo exclusivamente do indivíduo, ocultando-se os condicionantes sociais e históricos da conjuntura.

Outro aspecto revelador dos fundamentos político-ideológicos das DCNEM e de seus desdobramentos é a omissão quanto ao caráter necessa- 
Refundar o ensino médio? Alguns antecedentes e atuais desdobramentos das...

riamente diferenciado dos cursos noturnos. Os documentos oficiais, muito sintomaticamente, não se detêm nessa característica histórica do ensino médio brasileiro, não sugerindo qualquer abordagem que pudesse compensar a maior complexidade dos problemas enfrentados pela escola noturna. Essa tentativa de ignorar o caráter predominantemente noturno das redes estaduais de ensino médio vem a reboque do Plano Nacional de Educação (Brasil, 1997) que não previu, para o decênio, aumento de vagas para matrículas no ensino noturno regular. $\mathrm{O}$ objetivo implícito nessas orientações políticas é o de "diuturnizar" o ensino médio, minimizando essa faceta que nos coloca na contramão de outros sistemas educacionais, inclusive de países latino-americanos. Sem dúvida, seria social e pedagogicamente muito saudável se fosse possível diminuir rapidamente as matrículas no noturno nas redes estaduais. Todavia, uma vez que a grande parte dos cursos médios noturnos estaduais ocupa prédios que, durante o dia, são plenamente usados por alunos do ensino fundamental e médio, seria necessário muito investimento na rede física para suportar a arriscada aposta de expansão do ensino médio somente por meio de matrículas no diurno. Como não houve previsão orçamentária para tal tipo de expansão, é de se supor que o projeto seria outro. De fato, há indícios de que a aposta na "diuturnização" do ensino médio regular veio acompanhada, em diversos estados, do incentivo para que os alunos mais velhos optassem por cursos supletivos. ${ }^{3}$ Adicionalmente, as características extremamente perversas da distribuição da renda nacional não garantem que será possível, em médio prazo, à maior parte das famílias, evitar a submissão de seus filhos ao desgastante regime trabalho/escola, mesmo daqueles com idades entre 15 e 17 anos (faixa ideal para a freqüência ao ensino médio). Nesse cenário, parece explicitar-se o viés ideológico e político que está por trás da omissão dos documentos oficiais quanto às necessidades especiais dos cursos noturnos regulares de ensino médio. ${ }^{4}$

Além disso, no contexto da reforma, surpreende o fato de que o grande número de estudos referentes às DCNEM - estudos realizados com muito rigor científico e já referidos neste texto - não teve, até agora, como conseqüência, a multiplicação de pesquisas empíricas sobre a implementação da proposta. Ao contrário, são poucas as investigações que estabeleceram o objetivo de ir às escolas para acompanhar os desdobramentos institucionais das novas Diretrizes. Diante desse quadro ainda bastante insuficiente, vale destacar três estudos, os quais, embora 
metodologicamente distintos e focalizando diferentes momentos da implantação da reforma, trazem, mesmo assim, diversos dados convergentes. Os trabalhos aqui enfocados são os seguintes: a) Abramovay \& Castro (2003), que focalizaram, em 2001/2002, 673 escolas médias em 13 estados, com o objetivo específico de examinar a percepção dos diversos agentes escolares quanto aos objetivos e às condições de ensino da escola média, inclusive quanto à implementação da reforma; b) Zibas \& Krawczyk (2005), que, entre 2001 e 2004, acompanharam a implantação da reforma em 18 escolas, em 3 estados; c) Zibas et al. (2004), que enfocaram o protagonismo juvenil e dos pais no âmbito da reforma por meio de cinco estudos de caso, em dois estados, entre 2002 e 2003. tes dados:

Os resultados dessas investigações trazem, entre outros, os seguin-

- O investimento na recuperação da rede física e na ampliação dos recursos didáticos (bibliotecas, laboratórios e equipamentos de informática) foi muito pequeno para alavancar as condições de ensino. Material insuficiente, falta de recursos para manutenção e falta de tempo, de conhecimento ou de interesse dos docentes para manuseio dos equipamentos foram a tônica dos dados colhidos (a, b, c).

- Os professores têm pouca informação sobre a reforma, relacionando-a, em um primeiro momento, apenas ao material recebido, às mudanças nas grades curriculares e aos processos de avaliação $(a, b, c)$.

- A capacitação docente em serviço - mesmo naqueles estados que fizeram grande investimento nessa área - não estava tendo os desdobramentos desejados. A crítica dos docentes recaía sobre a fragmentação dos cursos e sobre a impossibilidade de comunicação entre os professores que deveriam ser os multiplicadores e seus pares. A rotina de trabalho, na maioria das escolas, continuava baseada na atuação individual, isolada, dos docentes (a, $b, c)$.

- A dedicação a duas ou três escolas e a conseqüente dispersão de esforços, com o atendimento de 600 até mil alunos por docente, foram fatores constantemente mencionados como impeditivos tanto para envolvimento efetivo na reforma quanto para identificação dos problemas de aprendizagem dos alunos. Nes- 
Refundar o ensino médio? Alguns antecedentes e atuais desdobramentos das...

se cenário, a coincidência de horários para reuniōes pedagógicas é difícil e os raros encontros são usados mais para decisões ou comunicações administrativas que para discussões pedagógicas $(\mathrm{a}, \mathrm{b}, \mathrm{c})$.

- A parte da grade curricular (25\%) que foi outorgada à competência da escola, para suprir as necessidades dos alunos de cada comunidade, tem servido, na verdade, para atender interesses docentes. Quando a escola procurou responder às demandas dos alunos e das famílias, não houve condições técnicas e/ou materiais para o atendimento (por exemplo, falta de equipamento e de especialista para cursos de informática) (b, c).

- Em 2003, foram notados alguns indícios de ampliação do envolvimento dos professores em projetos de cunho interdisciplinar. Tais projetos, na maioria dos casos, eram induzidos por órgãos centrais ou ONGs e eram considerados "extracurriculares", sendo, de toda forma, poucos os estudantes e os docentes participantes. Nesse contexto, a mera operacionalização de alguns projetos passou a significar adesão da escola à reforma, embora aspectos específicos, como o desenvolvimento de competências, a interdisciplinaridade e a contextualização, fossem conceitos não debatidos, não avaliados e, na maioria das vezes, desconhecidos dos docentes (b, c).

- A reforma da gestão, com incentivo para a participação de pais e alunos agora como "clientes", não conseguiu penetrar nos tradicionais procedimentos intramuros. Os estudantes e seus pais continuavam a participar de maneira apenas formal nos órgãos deliberativos, sendo chamados a contribuir mais efetivamente apenas no âmbito operacional, como na organização de festas e em mutirões para a limpeza da escola. No entanto, essa tradicional participação "operacional" foi alargada, em alguns contextos, para o alardeado estatuto de "amigos da escola", os quais foram encontrados pelos pesquisadores ministrando aulas de teatro, de educação física e até de química (b, c).

É, também, necessário considerar as conseqüências contraditórias das políticas dos anos de 1990 em seu esforço de introduzir - ainda segundo orientações internacionais - a "cultura da avaliação" no sistema. De uma parte, a iniciativa dos órgãos centrais de induzirem processos 
avaliativos intra-escolares que reduzissem a repetência, sem fornecer condiçôes materiais e técnicas adequadas para o sucesso de tais inovações, apenas incentivou a "promoção automática", sem garantia de um nível mínimo necessário de aprendizagem (Zibas et al., 2004). De outra parte, a introdução de avaliaçôes do sistema, por meio de exames como o ENEM e O SAEB, ou a participação de alunos brasileiros em testes internacionais, como o PISA, acaba trazendo indicações quanto à fragilidade do processo escolar e ao caráter inócuo da reforma.

Em artigo recente (Zibas, 2005), já me referi à tese de Guillermina Tiramonti sobre essa incontornável contradição criada pelas políticas dos anos de 1990. Vale a pena repeti-la, agora textualmente, em vista de seu desafiante potencial explicativo:

Hay un discurso que hace de la evaluación externa, de los resultados educativos, la llave fundamental para alcanzar sistemas de calidad. Al mismo tiempo, para mejorar los índices de retención escolar, se há neutralizado la función de la evaluación en la escuela. Aparentemente, sólo cabe la lectura de la contradicción. Sin embargo, me inclino a pensar que es una contradicción que se explica a partir de este cambio de rol de Estado que debe, por un lado, constituirse en un órgano para la vigilancia y disciplinamiento de los agentes del sistema, para lo cual la evaluación externa resulta un dispositivo adecuado y, por otro, garantizar la contención y el control de los necesitados, para lo cual su permanencia en la escuela resulta de suma utilidad. (Tiramonti, 2001, p. 15)

Diante da contradição entre a precariedade do processo de ensino e a inescapável adesão à avaliação sistêmica, os responsáveis pela reforma submetidos à pressão para o uso político dos resultados - parecem obrigados a um "contorcionismo", tanto no desenho da avaliação externa quanto na interpretação dos dados decorrentes. O artigo de Castro \& Tiezzi (2005) traz alguns indícios a respeito. Senão, vejamos.

Ao focalizar o Exame Nacional do Ensino Médio (ENEM), de 2002, esses especialistas apresentam resultados contraditórios dos dois testes que constituem a prova. As respostas dos alunos ao teste de questôes objetivas relativas a competências gerais estão dispersas, em 74\% dos casos, na faixa de 0 a 40 pontos (em uma escala de 100 pontos), ou seja, entre “insuficiente a regular". $\mathrm{Na}$ análise desses lamentáveis números, os autores apontam, como causa, entre outras, a falta de competência dos estudantes de lerem e entenderem o enunciado das questóes. Todavia, na pro- 
Refundar o ensino médio? Alguns antecedentes e atuais desdobramentos das...

va de redação, 72,3\% dos sujeitos obtiveram resultados de "regular a bom" (entre 40 e 70 pontos). Esse aparente enigma pode ser esclarecido pelo fato de que o "estímulo" à redação é feito por meio de quatro textos. Nas palavras dos autores: "De modo geral, nota-se que os participantes compreendem o tema da redação, mas na maioria das vezes (grifo meu) (...) ocorre apenas um processo de reescrita dos textos-estímulo para seus próprios textos". É com base nessa "colagem" que os analistas dos resultados concluem que os estudantes têm domínio "de regular a bom" (média de 61,3) na norma culta da língua, embora se reconheça que "grande parte dos participantes [tenha se limitado] a reproduzir os argumentos [e a forma?] dos textos-estímulo" (p. 140-142).

Outra técnica que tende a diluir os maus resultados se refere à adoção de escala contínua de 0 a 100 pontos para a apresentação dos dados. Ou seja, essa escala não é dividida em patamares bem definidos quanto a resultados "insuficientes", "regulares", "bons" e "excelentes", mas é apresentada em um continuum de "insuficiente a regular", "regular a bom", "bom a excelente". Dessa forma, a grande maioria - que obteve resultados até 40 pontos no teste objetivo, o que, pela lógica tradicional, seria considerado insuficiente - passa a ser classificada como "de insuficiente a regular”.

Quanto ao Sistema Nacional de Avaliação da Educação Básica (SAEB), a média dos alunos da $3^{a}$ série do ensino médio em 2001, para o conjunto do país, atingiu apenas 276,7 pontos, quando o mínimo adequado seria 375. Em 2003, esses resultados se confirmaram, com a média de 278,7 pontos (Fonte: MEC/INEP).

O esforço para atenuar as evidências trazidas pelas avaliações externas tem contribuído para a divulgação do conceito de "educabilidade", segundo o qual a pobreza reduz irremediavelmente o potencial de aprendizagem dos alunos (Tedesco, 2001a). Essa concepção tenta enfraquecer a relação que se pode estabelecer entre as reformas dos anos de 1990 e a contínua falta de aprendizagem da maioria dos estudantes, falta de aprendizagem não superada até mesmo no Chile, a decantada vitrine do modelo. ${ }^{5}$

O histórico da reforma, brevemente discutido neste texto, bem como os resultados do ENEM 2002, do SAEB 2001 e 2003 e das três pesquisas anteriormente comentadas parecem contribuir para o esboço de um quadro razoavelmente nítido das condições do ensino médio herdadas pelo Governo Lula. Para melhor dimensão dessa herança, no entan- 
to, faltou mencionar o aumento considerável das matrículas no período entre 1996 e 2002, o qual, segundo dados de MEC/INEP/SEEC, foi de 51,8\%, passando de 5.739.077 para 8.710.584.

Neste ponto, vale focalizar as perspectivas do ensino médio a partir de 2003. O primeiro registro diz respeito ao financiamento. Nesse aspecto, a instituição do Fundo de Manutenção e Desenvolvimento da Educação Básica (FUNDEB) significa a inusitada criação de uma fonte estável de recursos para a escola média, que tem, historicamente, sobrevivido apenas à sombra do financiamento do ensino fundamental ou, como no caso da recente reforma, atrelada à insegurança e ao alto custo dos empréstimos internacionais. Para a viabilidade do FUNDEB, foi recentemente encaminhada ao Congresso Nacional, pelo governo federal, uma Proposta de Emenda Constitucional (PEC). Em que pesem as críticas quanto a sua abrangência, que, conforme projeto oficial, excluiria o financiamento da educação infantil, o FUNDEB pode significar, para o ensino médio, a ampliação das matrículas e o resgate da qualidade. Todavia, trata-se de uma proposta em tramitação e muitos percalços podem acontecer, principalmente aqueles colocados por um novo aperto fiscal, que se prenuncia em face da gravidade da atual crise política.

Outra mudança anunciada refere-se ao atendimento das peculiaridades do ensino noturno, atendimento o qual, como já discutido, não entrou na lista de prioridades do governo anterior. $\mathrm{O}$ indício de um novo enfoque está na encomenda - feita pelo MEC a pesquisadores da USP - de levantamento e análise de experiências referentes aos cursos médios noturnos, regulares. O relatório final (Oliveira \& Sousa, 2004) inclui uma série de recomendações, as quais abrem perspectivas para enfrentamento dos problemas do noturno. Esse bom começo, no entanto, não garante, evidentemente, a concretização de políticas efetivas para a escola noturna, processo que deve ser acompanhado pela comunidade acadêmica.

No que concerne ao currículo, é preciso notar que continua em vigor a Resolução CEB/CNE n. 03/98, cujo teor, propondo a centralidade do desenvolvimento de competências, foi rigorosamente criticado pela comunidade acadêmica, como já comentado. É com base nessa Resolução que estão em debate, atualmente, os novos Parâmetros Curriculares Nacionais para o Ensino Médio. ${ }^{6}$

Quanto à "cultura da avaliação", talvez tenha sido intensificada no novo governo, a julgar pelo montante previsto para investimento na área. 
Refundar o ensino médio? Alguns antecedentes e atuais desdobramentos das...

De fato, em substituição ao SAEB, está prevista a introdução da Avaliação Nacional de Rendimento Escolar, que não mais usará o sistema de amostragem, mas submeterá à prova todos os alunos das $4^{{ }^{a} \mathrm{~s}}$ e $8^{\mathrm{as}_{\mathrm{s}}}$ séries do ensino fundamental e das $3^{\text {as }}$ séries do ensino médio. Em 2005, tal avaliação, ainda sem incluir o ensino médio, prevê atingir cerca de $5 \mathrm{mi}$ lhões de alunos de $4^{\text {as }}$ e $8^{a_{s}}$ séries matriculados nas 43 mil escolas da zona urbana. Serão cerca de R \$ 55 milhões contra os $\mathrm{R}$ \$ 6 milhões gastos pela avaliação por amostragem do SAEB. ${ }^{7}$

Especificamente com relação ao ENEM, vale registrar que prevalece a mesma estrutura da prova e de apresentação dos resultados, aqui já criticada com relação aos procedimentos do MEC no Governo Fernando Henrique Cardoso. Nesse quadro, repetem-se as mesmas contradições, principalmente quanto aos resultados da prova de redação, que podem ser questionados em vista da "colagem" permitida aos alunos a partir dos "textos-estímulo".

Todavia, se quisermos aprofundar o paralelo entre o projeto para o ensino médio do Governo Fernando Henrique e a atuação do Governo Lula na área, a primeira diferença a registrar é a característica monolítica e autoritária das políticas dos anos de 1990 ante a multiplicidade de enfoques em debate a partir de 2003. Na verdade, o Governo de FHC, muito antes de sua posse, já tinha quadros do partido (ou seus próximos) alinhados com as propostas dos organismos internacionais (já citamos os casos de Moura e Castro e de Guiomar Namo de Mello). Assim, a partir da posse, em 1995, passou-se, imediatamente, à implementação dos princípios já assumidos. A estratégia foi apenas a construção de uma "fachada" democrática, quando os principais eixos das políticas já estavam definidos e não admitiam desvios. Neste sentido, o Governo FHC foi competente, envidando todos os esforços para moldar, de forma irreversível, todo o sistema educacional aos modelos divulgados pelas instituições multilaterais. Embalada em seu início por empréstimos internacionais, a reforma do ensino médio decolou com algum fôlego, mas logo mostrou, como já discutido, a impossibilidade de melhoria da qualidade, em vista, principalmente, da descontinuidade da alocação de recursos e da desconsideração das reais condições de trabalho dos professores.

Após a instalação do Governo Lula, houve a preocupação de se estabelecer um debate amplo sobre o ensino médio e técnico, concretizado por meio de seminários e oficinas, entendidos, conforme Frigotto \& Ciavatta (2004b, p. 19), como "um processo vivo de reflexão e de socia- 
bilidade (...), abrindo o diálogo com a comunidade educacional em busca das melhores alternativas para os diferentes problemas existentes". Com tal abordagem, a coletânea Ensino médio: ciência, cultura e trabalho, publicada por MEC/SEMTEC (Frigotto \& Ciavatta, 2004a), que divulgou parte dos debates, traz à luz diferenças teóricas e político-ideológicas inconciliáveis entre os potenciais colaboradores do novo governo. Essas discrepâncias não estavam bem explicitadas no período anterior, quando as críticas às políticas do Governo Fernando Henrique tendiam a aproximar grande parte da comunidade acadêmica.

Assim é que, de um lado, há uma defesa muito firme de uma escola média que, mesmo respeitando as diferenças, tenha um perfil universal, calcado nas proposiçóes de Gramsci quanto à politecnia, combinando "trabalho, ciência e cultura na sua prática e nos seus fundamentos científico-tecnológicos e histórico-sociais" (Frigotto \& Ciavatta, 2004b, p. 18) ou, dito de outra forma, uma escola que garanta "o direito de acesso aos conhecimentos socialmente construídos, tomados em sua historicidade, sobre uma base unitária que sintetize humanismo e tecnologia” (Ramos, 2004, p. 41). Pressupõe-se, assim, a validade universal de um conhecimento que não se confunde com enciclopedismo porque, construído historicamente, evidencia a luta social que motivou seu avanço em um determinado tempo histórico, constituindo o "patrimônio da humanidade" (idem, ibid., p. 39-40).

A tal argumentação contrapõe-se outra concepção de currículo, que talvez se possa identificar como "pós-moderna”, defendida na mesma coletânea por Lopes (2004a), segundo a qual a validade universal de qualquer conhecimento transmitido pela escola é uma falácia, uma vez que:

É preciso sempre lembrar que a própria idéia de universal é uma invenção humana, situada em determinado momento histórico. O fato de um conhecimento ser considerado universal só se estabelece porque existem pessoas e relações sociais aos quais essa universalidade interessa. Se a perspectiva atual é construir um outro projeto de educação e de sociedade, penso ser preciso começar questionando os padrões "universais" de conhecimento escolar até hoje instituídos. (p. 203)

Nessa abordagem, não há possibilidade de um currículo nacional e, portanto, descarta-se o princípio da escola unitária. Além disso, entendido como política cultural, o currículo deve abordar o trabalho ape- 
Refundar o ensino médio? Alguns antecedentes e atuais desdobramentos das...

nas como uma questão entre muitas outras (tais como: gênero, sexualidade, juventude, violência, lazer etc.), deixando de ser o princípio educativo por excelência proposto por Gramsci.

Em meio a essas disputas teóricas - as quais, evidentemente, não são novas, mas que estão agora mais bem definidas entre nós - o Decreto n. 5.154 , de 23 de julho de 2004, instituiu a possibilidade de reintegração entre ensino médio e técnico-profissional. A não-obrigatoriedade de reversão da dualidade estabelecida no Governo Fernando Henrique contrariou diversos críticos, mas foi explicada pelo custo financeiro e político de tal reversão, uma vez que a estrutura imposta pelas políticas dos anos de 1990 já estaria consolidada.

Kuenzer (2004, p. 114) vê com alguma desconfiança o Decreto n. 5.154 que possibilitou a reintegração, argumentando que será "o financiamento, o que só poderá ser avaliado mais adiante (...) [ou] o montante de recursos investidos pelo governo na expansão da versão integrada com qualidade, o indicador de suas verdadeiras intençôes". No mesmo texto, a autora revisita o debate dos anos de 1980 sobre escola unitária e politécnica e identifica o "fio da navalha" em que se caminhou naquele período, quando as categorias de análise conhecidas apontavam para a impossibilidade da instalação do modelo no contexto capitalista ao passo que, ao mesmo tempo, prosperava entre os estudiosos o apego à possibilidade de saídas universais, dentro "da lógica da ocupação dos espaços derivados das contradiçóes, enquanto estratégias de transição" (p. 101). No contexto atual, preocupada em evitar o "voluntarismo" que, de certa forma, permeou o embate na década de 1980 e ciente de que o perfil universal da escola média, tal como estipulado pelo Decreto n. 2.208/97, pode significar o acirramento das desigualdades, Kuenzer propóe que, no plano político, reafirme-se a defesa da escola unitária, que não diferencie os alunos a partir de sua origem de classe, mas que, no âmbito da prática, "tendo a clareza da impossibilidade histórica de objetivação desta escola no capitalismo (...) [caminhe-se para] políticas afirmativas e, portanto, específicas para trabalhadores (...) enquanto conquistas parciais no processo de transição (...)” (p. 108).

Resta distinguir melhor como essas posições (de Kuenzer [2004], Ramos [2004] e Frigotto \& Ciavatta [2004b]) se relacionam com a reintegração proposta pelo Decreto n. 5.154. O que se nota é que Ramos e Frigotto \& Ciavatta assumem, talvez apenas estrategicamente, a possibilidade da construção imediata da escola unitária e politécnica, ao passo 
que Kuenzer insiste em uma abordagem escalonada, de transição. Tal distinção pode referir-se somente aos lugares de onde partem esses discursos, uma vez que Ramos (como integrante, naquele momento, da SEMTEC) e Frigotto \& Ciavatta (como consultores privilegiados) falavam a partir do locus de construção das políticas, ao passo que Kuenzer falava a partir da academia. De todo modo, os históricos defensores de uma escola média unitária - inspirada em Gramsci, tendo o trabalho como princípio educativo -, embora continuem críticos quanto à timidez e às contradições das políticas, parecem agora apostar na possibilidade de uma aproximação a esse projeto.

Como contraponto, os estudiosos que adotam a abordagem aqui definida como "pós-moderna", se mostram muito mais céticos quanto à democratização do ensino médio, apontando, como um dos empecilhos, a permanência, nos órgãos oficiais, da "mesma comunidade epistêmica" do governo anterior (Lopes, 2004b).

Em parte, os atuais enfrentamentos teóricos, políticos e ideológicos desdobram-se no registro de três perfis possíveis para o ensino médio:

a) a continuação, como no estado de São Paulo, da estrutura dual prescrita pelo Decreto n. 2.208 de 1997;

b) algumas experiências, como no estado do Paraná, de implementação da escola unitária e politécnica;

c) em outros estados, há possibilidade de reintegração entre o ensino médio e técnico conforme modelo vigente antes da legislação de 1997.

Esse cenário polimorfo - que pode causar alguma disfuncionalidade administrativa, além de uma certa perplexidade conceitual - constitui, todavia, um desafio estimulante para pesquisadores do ensino médio em seu incessante trânsito entre a teoria e a observação e análise das práticas sociais, políticas e pedagógicas.

Em resumo, pode-se dizer que as contradições do atual processo além de explicitarem melhor a distância entre os diferentes grupos que foram críticos das políticas dos anos de 1990 - apontam para: a) a possibilidade de um financiamento estável do ensino médio por meio do FUNDEB; b) uma aproximação a antigas bandeiras progressistas, em paralelo com concessôes à dualidade estrutural conservadora e à pedagogia das competências; c) a possibilidade de uma discriminação positiva dirigida ao ensino noturno; d) a acentuação da "cultura da avaliação", 
Refundar o ensino médio? Alguns antecedentes e atuais desdobramentos das...

com maiores gastos na área. O desenvolvimento desse quadro contribuirá para a definição dos limites da construção de políticas democráticas para o ensino médio.

\section{Recebido e aprovado em agosto de 2005.}

\section{Notas}

1. Como se sabe, a autora Maria Helena Guimarães de Castro foi titular do INEP no Governo FHC.

2. Zibas (2005) traz referências das principais críticas produzidas sobre a reforma curricular.

3. No Ceará, por exemplo, a instituição do TAM - Tempo de Avançar -, destinado à escolaridade mais curta de alunos maiores de 18 anos, chegou a ser denunciada à Relatoria Nacional do Direito Humano à Educação como forma privilegiada pela Secretaria de Educação para a universalização do ensino médio (Haddad \& Graciano, 2003).

4. No cenário dos cursos noturnos, para evitar qualquer tendência de maior simplificação e precariedade, convém lembrar, mais uma vez, Tedesco (2001b), quando diz que para lidar com situações de pobreza os esquemas não podem ser simplificadores, mas ricos e diversificados.

5. Sobre os constantes maus resultados dos alunos nas avaliações do sistema educativo chileno (SIMCE), as fontes consultadas foram as seguintes: a) o documento do Colegio de Prefesores de Chile, de 7 de abril de 2004, intitulado "Declaraciones públicas del Directorio Nacional", consultado em 15 de abril de 2004 no site <www.colegiodeprofesores.cl>; b) a polêmica divulgada na rede ComunidadEducativa@gruposyahoo.com.ar, em 14 de maio de 2005, entre o sociólogo José Joaquin Brunner e o economista Claudio Sapelli.

6. O documento para debate está no portal do MEC, consultado em 29 de julho de 2005.

7. Fonte: Folha On Line, 25 jul. 2005 - entrevista com a coordenadora-geral do Sistema Nacional de Avaliação da Educação Básica do INEP, Luiza Massae Uema.

\section{Referências bibliográficas}

ABRAMOVAY, M.; CASTRO, M. Ensino médio: múltiplas vozes. Brasília, DF: MEC/UNESCO, 2003.

BRASIL. Ministério da Educação. Plano Nacional de Educação. Brasília, DF: MEC/INEP, 1997.

CASTRO, M.H.G.; TIEZZI, S. A reforma do ensino médio e a implantação do enem no Brasil. In: Brock, C.; SChWARTZMAN, S. (Org.). Os desafios da educação no Brasil. Rio de Janeiro: Nova Fronteira, 2005. p. 119-154. 
CUNHA, L.A. As agências financeiras internacionais e a reforma brasileira do ensino técnico: a crítica da crítica. In: Zibas, D.M.L.; AgUiar, M.A.S.; Bueno, M.S.S. (Org.). O ensino médio e a reforma da educação básica. Brasília, DF: Plano, 2002. p. 103-134.

DUBET, F. A escola e a exclusão. Cadernos de Pesquisa, São Paulo, n. 119, p. 29-46, jul. 2003.

FRIGOTTO, G.; CIAVATA, M. (Org.). Ensino médio: ciência, cultura e trabalho. Brasília, DF: MEC/ SEMTEC, 2004a.

FRIGOTTO, G.; CIAVATTA, M. A busca de articulação entre trabalho, ciência e cultura no ensino médio. In: Frigotto, G.; Ciavatta, M. (Org.). Ensino médio: ciência, cultura e trabalho. Brasília, DF: MEC/SEMTEC, 2004b. p. 11-34.

GHIRALDELli JR., P. História da educação. São Paulo: Cortez, 1994.

HADDAD, S.; GRACIANO, M. O direito à educação no Brasil. São Paulo: Relatoria Nacional do Direito Humano à Educação, 2003. (mimeo.).

KUENZER, A.Z. Políticas do ensino médio: continuam os mesmos dilemas. In: Costa, A.O.; Martins, A.; Franco, M.L.B.P. (Org.). Uma história para contar: a pesquisa na Fundação Carlos Chagas. São Paulo: Annablume, 2004. p. 89-116.

LOPES, A.C. Interpretando e produzindo políticas curriculares para o ensino médio. In: Frigotto, G.; Ciavatta, M. (Org.). Ensino médio: ciência, cultura e trabalho. Brasília, DF: MEC/SEMTEC, 2004a. p. 191-206.

LOPES, A.C. Políticas curriculares: continuidade ou mudança de rumos? Revista Brasileira de Educação, Rio de Janeiro, n. 26, p. 109-118, $2004 \mathrm{~b}$.

MELLO, G.N. Social democracia e educação. São Paulo: Cortez, 1990.

MOURA E CASTRO, C. Educação técnica: a crônica de um casamento turbulento. In: Brock, C.; SChwartzman, S. (Org.). Os desafios da educação no Brasil. Rio de Janeiro: Nova Fronteira, 2005. p. 153-180.

MOURA E CASTRO, C. O ensino médio esquecido em um desvão do ensino? In: SEMINARIO INTERNATIONAL DE AVALIAÇĀO DA EDUCAÇÃO, Rio de Janeiro, 1995. Anais... Brasília, DF: MEC/INEP, 1995. 
Refundar o ensino médio? Alguns antecedentes e atuais desdobramentos das...

OLIVEIRA, R.P.; SOUSA, S.Z. Ensino médio noturno: registro e análise de experiências. São Paulo: USP/MEC, maio 2004. (Relatório de pesquisa)

RAMOS, M.N. O projeto unitário de ensino médio sob os princípios do trabalho, da ciência e da cultura. In: Frigotto, G.; Ciavatta, M. (Org.). Ensino médio: ciência, cultura e trabalho. Brasília, DF: MEC/SEMTEC, 2004. p. 37-52.

RAMOS, M.N. A pedagogia das competências e a psicologização das questôes sociais. São Paulo: IIEP, [s/d.]. (mimeo.).

SPOSITO, M. O povo vai à escola. São Paulo: Loyola, 1984.

TEDESCO, J.C. Informe: quedándonos atrás. Santiago: Programa de Promoción de la Reforma Educativa en América Latina y el Caribe, 2001a.

TEDESCO, J.C. Introducción: los cambios en la educación secundaria y el papel de los planficiadores. In: Braslavsky, C. (Org.). La educación secundária: cambio o immutabilidad? Buenos Aires: Santillana, 2001 b. p. 11-20.

TIRAMONTI, G. Modernización educativa de los 90. Buenos Aires: FLACSO; Temas Grupo, 2001.

ZIBAS, D.M.L. A reforma do ensino médio nos anos 1990: o parto da montanha e as novas perspectivas. Revista Brasileira de Educação, Rio de Janeiro, n. 28, p. 24-36, 2005.

ZIBAS, D.M.L.; FERRETTI, C.; TARTUCE, G. O protagonismo de alunos e pais no ensino médio. São Paulo: Fundação Carlos Chagas, 2004. (Textos FCC, 25)

ZIBAS, D.M.L.; KRAWCZYK, N. Acompanhamento e avaliação interativa da implantação das novas políticas de gestão do ensino médio: relatório de pesquisa. São Paulo: Fundação Carlos Chagas, 2005.

1086 Educ. Soc., Campinas, vol. 26, n. 92, p. 1067-1086, Especial - Out. 2005 